Francis Corblin

UHB Rennes 2 \&

Laboratoire de linguistique formelle

2, Place Jussieu

75005 Paris

corblin@paris7.jussieu.fr

\title{
Complexity and compositionality in multiple negation
}

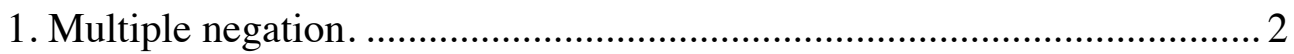

1.1. The compositionality problem ................................................ 2

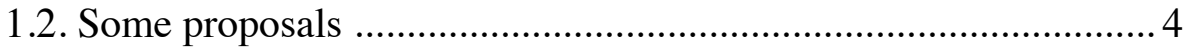

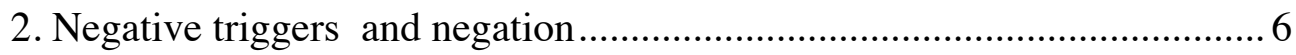

2. 1. Representation and interpretation of negative sentences in DRT 6

2.2. Negative triggers ............................................................... 7

2.3. Basic Construction Rule for negative quantifiers......................... 9

3. The interpretation of multiple negation sentences ................................ 11

3.1. Sentences with two negative quantifiers .................................. 11

3.2. Sentences with more than two negative quantifiers ................... 16

3. 3. Parasitism as a complexity regulator ........................................ 19

4. On the Complexity of negation auto-embedding .................................. 21

4.1. Classical double negation elimination ....................................... 21

4.2. Complex negation auto-embedding ...................................... 22

4.3. Multiple negation with trigger and quantifiers ...........................25

4.4. No parasitism cases ............................................................... 32

5. Conclusion and perspective for further research ..................................... 38

\section{Abstract:}

A French sentence like Personne n'aime personne [nobody-loves-nobody] is notoriously ambiguous: it can be true in no-love worlds (i) or in worlds within which everybody loves somebody (ii). (ii) seems fully compositional, while the preferred interpretation (i) is not.

This paper introduces a principled algorithm for deriving the representation of sentences with multiple negative quantifiers in a DRT framework (Kamp \& Reyle, 1993). The algorithm is controlled by a regulating mechanism keeping the complexity of negation autoembedding below a threshold of complexity exemplified by (ii); this mechanism is seen as a competence limitation imposing (and licensing) the "abrogation of compositionality" (May 1989) observed in the so-called negative concord readings (Labov 1972, Zanuttini 1991, 
Ladusaw 1992). Theoretical arguments about the complexity of those structures, as well as empirical observations about contexts excluding one of the readings (i) and (ii) are given in support of this view. 


\section{Complexity and compositionality in multiple negation}

\section{Introduction}

One way of giving a semantics for natural language is to provide effective procedures for the translation of Natural Language sentences into the formulae of a logic. A semantic representation (SR) of a sentence $\mathrm{S}$ in a formal language is a formula accepted as a correct translation of $\mathrm{S}$.

NATURAL LANGUAGE

Sentence $->\quad$ FORMAL LANGUAGE

Formula

The association of those two syntactic objects (a sentence and a formula) provides a semantics for the sentence in the following way: if a SR of $\mathrm{S}$ is valid in such and such models, and if those models mirror exactly the real situations or states of information in which $\mathrm{S}$ is accepted as true, such a SR is an empirically correct translation of S.

Most varieties of formal semantics have put more constraints on the principles governing the production of empirically adequate translations of natural language sentences. The best known of those constraints is Montague's strong version of Frege's compositionality principle. Montague's basic methodological axiom is that translation procedures of $\mathrm{S}$ - as well as interpretation rules for SR - should be homomorphisms. The importance of giving a fully compositional account of natural language is that if we succeed, we can give a direct justification of language efficiency and learnability: language works efficiently, and can be learned easily because its form-meaning mapping is governed by simple and rigid principles.

The substantial move done by Discourse Representation Theory (Kamp, 1981, Heim 1982) is the introduction of a dynamic view of meaning in formal semantics. The process by which a $\mathrm{SR}$ is obtained from the processing of syntactic input is seen as an incremental updating of a previously established information structure; this process itself is a characterization of the meaning of the linguistic structure. In this view, the notion of translation rules is replaced by more complex "Construction Rules" that are instructions for updating representations ${ }^{1}$. The

\footnotetext{
${ }^{1}$ Such representations are not representations of sentences, but representations of sequences of sentences (Discourses).
} 
formal language introduced by DRT for SR, the DRS languag, can be seen as a formal language designed for dynamic approaches of SR construction. It was originally introduced as a solution to problems with compositionality in the analysis of anaphora.

In this paper, I will propose an analysis of some natural language data which are at face value a problem for compositionality, namely sentences with multiple negative (or at least potentially negative) triggers. The paper provides a general algorithm schema for the mapping of negative triggers of a natural language (French) onto semantic representations. The formal language used for semantic representation is Kamp and Reyle's version of DRT (1993).

Moreover, I will try to give a principled solution to this problem in terms of a threshold of complexity on the on-line construction of a special kind of auto-embedded negative structures. This proposal has enough flexibility to cover negative concord languages as well as non-negative concord languages.

\section{Multiple negation}

\subsection{The compositionality problem}

In this section, I will introduce the general problem of multiple negation, postponing a more precise and detailed approach to the next sections.

The main issue in focus is the interpretation of sentences like (1):

(1) Nobody loves nobody

According to May (1989), in one of its readings, (1) is true in no-love worlds, which, as May puts it, looks like an "abrogation of compositionality". Roughly speaking: we have two negatives in (1), and in the SR of (1) we get only one negation.

In the so-called "negative concord languages" (from Labov 1972), such a derogation would be a rule; in those languages, the semantic negation of a clause is achieved by means of multiple occurrence of constituents expressing negation in their own right ${ }^{2}$ :

(2) Nobody said nothing to nobody

(non standard English)

(3) Mario non ha parlato di niente con nessuno (standard Italian)

(4) No m'ha telephonat ningu'

(Catalan)

\footnotetext{
2 This characterization of negative-concord and the examples (2-3) are due to Ladusaw (1992).
} 
In a language like French, sentences corresponding to (1) are ambiguous: they can have, besides the above mentioned "no-love world" reading, an "Everybody loves somebody" reading.

(5) Personne n'aime personne

[Nobody- loves- nobody]

Readings: $1 .(=$ No-love world $)$

$$
\text { 2. (= Everybody loves somebody) }
$$

Even without using any explicit representation at the moment, it seems that this extra-reading paraphrased in 5(2) will be much easier to derive as a composition of two negations than 5(1); at least in this weak sense, 5(2) seems compositional, while 5(1) is not.

Nevertheless, although a simple French sentence can contain more that two negative constituents, it is not likely that the SR of the sentence can get that many negations. For instance, passing from (6) to (7), the reading is not affected by an additional negative:

(6) Personne ne dit rien

[Nobody- says- nothing]

Readings: $1 .(=$ dumb world $)$

$$
\text { 2.(= Everybody says something ) }
$$

(7) Personne ne dit rien à personne

[Nobody- says- nothing-to nobody]

Readings: $1 .(=$ dumb world $)$

2.(= Everybody says something to somebody)

Although (7) has another negative constituent than (6), both get similar readings.

The compositionality problem can be stated as follows: each constituent in focus in (1)-(7) is assumed to be negative in the sense that its occurrence in a simple clause is a sufficient condition for the representation of the clause to be a negative formula; nevertheless, when we get more than one such constituent, we don't necessarily get the representation of the whole as a function of all of its parts. Compared to the strong notion of compositionality used by Montague, based on homomorphism, a weaker notion would be violated in this case, namely the functional nature of the interpretation relation.

\subsection{Some proposals}

I will not try to review here any proposal in details but I will try to characterize very briefly different available strategies. ${ }^{3}$

\footnotetext{
${ }^{3}$ For a detailed discussion of different proposals for "negative concord" see Ladusaw (1992).
} 


\subsubsection{The ambiguity hypothesis}

One may think that the compositionality problem does not exist at all if two interpretations are allowed for the considered expressions: true negatives/negative polarity items; but I think it is only an illusion. The best this theory can do is to justify some readings; its main empirical weakness is that it cannot rule out many impossible readings. Generally speaking, such a theory could predict that interpretations like (8) are licensed:

\begin{tabular}{ccc}
\multicolumn{1}{c}{ NEG } & NEG & NEG \\
$\exp _{1}$ & $\exp _{2}$ & $\exp _{3}$ \\
NPI & $\underline{\text { NPI }}$ & $\underline{\text { NPI }}$
\end{tabular}

Any NPI has to be licensed; the interpretation NPI is thus ruled out for $\exp _{1}$; and licensed for $\exp _{2}$, $\exp _{3}$, etc. Any other interpretation is theoretically open, so (8), besides a negative concord reading, should have readings with two, three, etc., negations, which is not the case. The ambiguity hypothesis in itself would be thus of little interest on empirical grounds; from a theoretical point of view, it cannot recommend itself on any intuitive basis: why should we have a systematic ambiguity negative/negative polarity item? If true, this would be precisely something we should ask a theory to account for. It is thus of no use to note here that this hypothesis can be falsified for some languages (e.g. French, Cf infra 4.3).

\subsubsection{The factorisation/absorption hypothesis}

Many proposals about negative concord share the assumption that each constituent is negative in its own right, and that some specific rule achieves a negation absorption or factorisation when there are many such constituents in a syntactic domain (May 1989, Haegeman and Zanuttini 1990, Zanuttini 1991).

The guide lines of May's 1989 proposal are as follows: when two identical occurrences of a monadic quantifier no occur within a syntactic domain, they can be interpreted in the standard way, but they can also be interpreted as one quantifier of a higher type (polyadic); this polyadic quantifier NO quantifies over pairs of individual, and asserts that there is no such a pair (hence the no-love world interpretation) ${ }^{4}$.

It sounds like a very ingenious way to solve the compositionality problem: instead of saying that one negation is lost, it says that with two simple negations we can build a more powerful one (quantifying on pairs). But it is actually based on an absorption rule, and any rule of that kind is overtly non-compositional, so although it can be empirically correct, it seems to me that in order to be considered as a principled translation procedure, it has to give some sort of

\footnotetext{
${ }^{4}$ Ladusaw (1992:7) shows convincingly in analysing Haegeman and Zanuttini's 1990 formulations that in this case, formulations in terms of "factorisation", are in fact negation absorption analyses.
} 
answer to the following question: why should absorption/factorisation be licensed (or obligatory) in that particular case of negative constituents in a single clause?

\subsubsection{The concord hypothesis}

In Ladusaw (1992), a more sophisticated strategy is introduced. N-words in negative concord languages are seen as negative polarity items (Cf. Laka 1990) : none of them expresses negation, and there is in fact no visible formative expressing negation. If my interpretation of Ladusaw's proposal is correct, the line of explanation is roughly the following: all the expressions under consideration are indefinites NPIs ; so they must be licensed by a negation operator. Where does this operator comes from, and how is it expressed? Each expression is associated with a feature [neg] governed by the head feature convention of GPSG (Gazdar et al.(1985)); so this feature will be shared by every projection of this lexical head. This analysis seems to take seriously the notion of negative concord, seeing the problem as an agreement phenomenon. A direct consequence of this analysis is that only a single negation will be allowed in a clause.

There are many problems with this strategy too. Firstly, if one accepts it, one has to buy some sort of feature analysis for negation and one has to buy the idea that there is some agreement constraint relating negation and indefinites. Moreover, this strategy is designed for negative concord languages, and cannot apply to other languages. As Ladusaw himself puts it, if we find "evidence that individual instances of those items express independent negations within the same clausal domain", this counts as evidence that those items express negation. This is exactly the case of sentence 5(b). Nevertheless, the very same sentence can also be interpreted as expressing one negation, like in 5(a).

\subsubsection{Common observation and problems with proposals}

If we try to abstract from different theories and different languages, a common observation emerges which is as follows:

(9) A common observation about multiple negation:

\section{$n$ (potentially) negative unary quantifiers in a single clause tend to reduce to one n-ary negative quantifier.}

Even if in some languages we can have such sentences with two negations, a general fact seems to be that those readings are less natural, and that readings with more than two negations do not exist (Cf. supra examples (1-7) and infra section 3).

If we consider this observation and the different strategies available in the literature in order to account for this observation, we are left with two issues:

1. Theoretical motivation. Why does such a tendency exist? What does this prima facie violation of compositionality reveal about the form/meaning relationship in natural language? 
2. Empirical adequation. If the tendency seems general, differences can be observed, within given languages and across languages, which are in need of careful inspection.

\section{Negative triggers and negation}

\section{1. Representation and interpretation of negative sentences in DRT}

Kamp and Reyle's 1993 version of DRT will be used as a formal language for the representation of negative sentences, as well as the classical semantics they associate with those negative representations.

The representation of the negative sentence (10) is the DRS (11):

(10) Jones does not own a Porsche

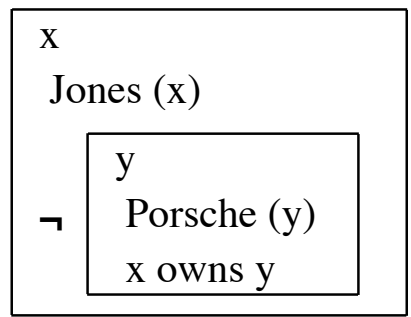

The DRS (11) is made of a top level DRS with a universe containing a discourse marker, and two conditions, Jones $(x)$, and a negative condition, namely a DRS prefixed with the symbol "ᄀ".

This negative DRS in its turn has a universe of its own, and two conditions. The indefinite NP a Porsche has its discourse marker in the universe of this negative DRS, which corresponds to the interpretation of the indefinite NP in the scope of the negation. Any negative DRS being a part of a condition, auto-embedding is allowed; a negative DRS can occur as a condition of a negative DRS, and so on.

The recursive verification algorithm for negative DRSs (12) from Kamp and Reyle (1993) will be used throughout this paper as a means to give an interpretation for any DRS containing negative conditions.

\section{(12) Verification algorithm for a DRS (from Kamp and Reyle 1993)}

Let $\mathrm{K}$ be a DRS, confined to a vocabulary $\mathrm{V}$, and a set $\mathrm{R}$ of discourse markers. $\mathrm{K}$ is a pair $\mathrm{U}$, (a subset of $\mathrm{R}$ ), Con $\mathrm{K}$ (a set of conditions).

$\mathrm{f}$ is a mapping function from $\mathrm{U}$ to $\mathrm{M}$, the universe of a Model $\mathrm{M}$.

1) $f$ verifies the DRS $K$ in $M$ iff $f$ verifies each of the conditions of $K$.

2) $f$ verifies the condition $C$ in $K$ iff:

a) $C$ is of the form $x=y$ and $f$ maps $x$ and $y$ onto the same element of $U_{M}$.

b) $\mathrm{C}$ is of the form $\mathrm{P}(\mathrm{x}, \mathrm{y}, \ldots), \mathrm{P}$ being a $\mathrm{n}$-ary predicate in $\mathrm{V}$, and $\mathrm{f}$ maps $(\mathrm{x}$, 
$y, \ldots)$ onto a $n$-tuple of $U_{M}$ belonging to the extension of the corresponding predicate in $\mathrm{M}$

c) $\mathrm{C}$ is of the form $\neg \mathrm{K}^{\prime}$, and there is no mapping $\mathrm{g}$ from $\mathrm{R}$ into $\mathrm{M}$ which extends $\mathrm{f}$, such that $\operatorname{Dom}(\mathrm{g})=\operatorname{Dom}(\mathrm{f}) \mathrm{U} \mathrm{UK}^{\prime}$ and $\mathrm{g}$ verifies $\mathrm{K}^{\prime}$ in $\mathrm{M}$

Consider for instance (11); in order to verify this DRS in a given model, it must be the case that $x$ can be mapped onto an individual $X$ of $U_{M}$ such that $X$ belongs to the extension of Jones, and it must be the case that no extension $g$ of this mapping (e.g., no function also mapping $x$ on $X)$ will be a mapping $(x, y)$ onto $(X, Y)$ such that $Y$ is in the extension of Porsche, and $(X, Y)$ is in the extension of owns.

\subsection{Negative triggers}

Let us call negation the symbol of the formal language; a negative trigger (we will often say just negative) is a natural language item translated as a negation.

More precisely we will assume the following definition:

\section{(13) Negative}

A negative is a member of a set of expressions $\mathrm{S}$ such that the occurrence of a unique member of this set in a simple sentence is necessarily translated as a negation.

Note that this definition can count a discontinuous expression as one negative (and not two). We will consider mainly negative triggers in French.

In modern French, the basic negative trigger is (ne) $\mathrm{V}$ pas, ne being facultative in many dialects, especially in the spoken language. We will make the hypothesis that pas is a negative trigger, $n e$ being an (optional) expletive form, i.e., a form with no contribution of its own to the construction of the SR; if this assumption is wrong, then the only risk is that everything that we will say may be valid only for those dialects of French without ne. Pas is adverbial, and thus can occur only once in a single clause.

If a sentence gets a representation containing a negation, it will be called a negative sentence. It is worth noting that one must distinguish between a negative sentence and a sentence accepting easily a negative paraphrase: ${ }^{5}$

\footnotetext{
${ }^{5}$ For more about the difference between expressions as don't like and dislike, see Linebarger (1980).
} 

(14) Jean n'a pas accepté
negative sentence
[Jean did not accept]
(15) Jean a refusé
positive sentence
[Jean refused]

There is at least one important difference between the two sentences (14) and (15), although they are valid in the same possible worlds: in the negative sentence (16) an indefinite NP argument of the verb can be interpreted in the scope of the negation (in its universe, in DRT language), whereas in (17) it is impossible:

(16) Jean n'a pas accepté une étudiante cette année

[Jean did not accept a female student during this year]

(17) Jean a refusé une étudiante cette année

[Jean refused a female student during this year]

(16) and (17) can be synonymous, involving then a particular female student, who can be mentioned by a singular anaphoric pronoun in a following sentence; but only (16) can also mean that no female student has been accepted by Jean during the year. Roughly speaking, only (16) builds a negative DRS with a universe such that the indefinite could be a filler of this universe. In (17), no such universe exists. The dynamics of ne pas accepter and refuser are thus different. The difference is confirmed by the distribution of aussi and non plus.
(18) Jean n'a pas accepté. Marie non plus
(19) Jean n'a pas accepté. *Marie aussi
(20) Jean a refusé
*Marie non plus
(21) Jean a refusé
Marie aussi

Non plus requires the presence of a negative in the previous sentence whereas aussi is prohibited if a negative trigger is present.

According to those criteria, there is another class of negative triggers in French, including the following expressions: rien, personne, aucun $N$, jamais, nulle part.

(22) Personne n'a accepté une étudiante à son séminaire

[Nobody- accepts -a female student-to her seminar]

(23) Personne n'a accepté. Marie non plus

Personne n'a accepté. *Marie aussi

In (22), the indefinite une étudiante can be interpreted in the scope of the negation; non plus 
is licensed and aussi is prohibited in a parallel subsequent sentence.

In order to fix a terminology for this paper, from now on I will distinguish between:

Negative triggers:

(25) Negative quantifiers pas

rien, personne, aucun $\mathrm{N}$, jamais.

Negative quantifiers function as major constituents in the sentence, either as arguments or as spatio-temporal adverbials. The consequence we would expect is that negative quantifiers can co-occur in a simple sentence, and can co-occur with a negative trigger. This is the case in French, hence the multiple negation sentences.

(26) Multiple negation sentence

Simple sentence (one finite verb) with more than one negative

\subsection{Basic Construction Rule for negative quantifiers}

A simple construction rule for negative quantifiers produces an adequate SR for simple sentences with one negative quantifier :

\section{(27) Proposal 1: Construction Rule for negative quantifiers}

\section{(CR-Neg-Q)}

1 - Represent the sequence in process as a negative DRS $\mathrm{K}_{1}$;

2 - interpret the constituent as an indefinite introducing its reference marker in the universe of the negative DRS $\mathrm{K}_{1}$.

Proposal 1 correctly predicts that (28) has the same interpretation as (29) with a narrow scope interpretation of the indefinite in (29).

(28) Jean n'a pas accepté une fille à son séminaire cette année

[Jean-did not accept-a girl- in his seminary this year]

(29) Jean n'a accepté aucune fille à son séminaire cette année

[Jean-accepted- no-girl- in his seminary this year]

Moreover, it seems that the expected consequences on anaphora of such a representation do hold: anaphora to the postulated discourse referent is licensed from the negative DRS, as in (30), but not from a subsequent sentence, as in (31):

(30) Aucun garcon n'admet qu'on le critique

[No boy-admits-that-he is criticized]

(31) *Aucun garcon n'est venu. On le critique

[No boy-came. He is criticized] 
Many languages have other lexical phrases of that kind, besides negative triggers like pas, namely expressions in argument or adverbial position, for which the above construction rule (27) produces correct representations.

The peculiarity of the construction rule defining such expressions (CR Neg-Q) can be illustrated by a comparison; due to $\mathrm{CRNeg-Q}$, (32) will receive the same representation as (33) with a narrow scope indefinite; this interpretation is given in (34):

(32) John n'a pas lu un livre

[John-did not-read-a book]

(33) John n'a lu aucun livre

[John-read-no book]

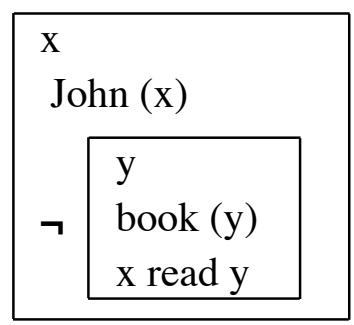

In the case of (32), this representation is derived with two independent Construction Rules, namely the rule for the negative trigger pas, which builds a negative DRS, and the rule for the indefinite un livre which can fill this DRS. In the case of (33), a single rule proceeding in two steps is doing the job: firstly a negative DRS $\mathrm{K}_{1}$ is created, then this DRS receives a negative marker bound by two conditions inside that DRS. Negative quantifiers are so to speak doing two things at once: they create a negative DRS (as negative triggers do) and then, they fill it with a Reference Marker (as an indefinite in the scope of a negative would do). This formalization is a way of capturing the analysis of negative quantifiers as negative indefinites (i.e. as an existential quantification in the scope of a negation), which is well represented in the literature (Cf. among others Zanuttini 1991, Ladusaw 1992). Moreover, it does not introduce any complication in the reference framework; the distinction in DRT between DRS-builders (conditional, negation) and DRS-fillers (indefinite) is available; moreover the analysis of Universally quantifying NPs in DRT (every $N$ ) considers them as DRS-builders-fillers, which is exactly the status we give to negative quantifiers in our representation.

\section{The interpretation of multiple negation sentences}

I will concentrate first on the co-occurence of negative quantifiers in simple sentences (3.13.2 ), considering later (4.3) the co-occurence of negative trigger and negative quantifiers in 
the same sentence.

\subsection{Sentences with two negative quantifiers}

The observation that sentences with two negative quantifiers are ambiguous has been made several times in the literature about French (cf. Muller 1987), most often about sentences with negative quantifiers in subject and object position, like (5). Using the DRT language, the two interpretations of the sentence are correctly represented by the following DRSs; a predicate logic paraphrase of each interpretation, as well as an informal paraphrase in English are provided.

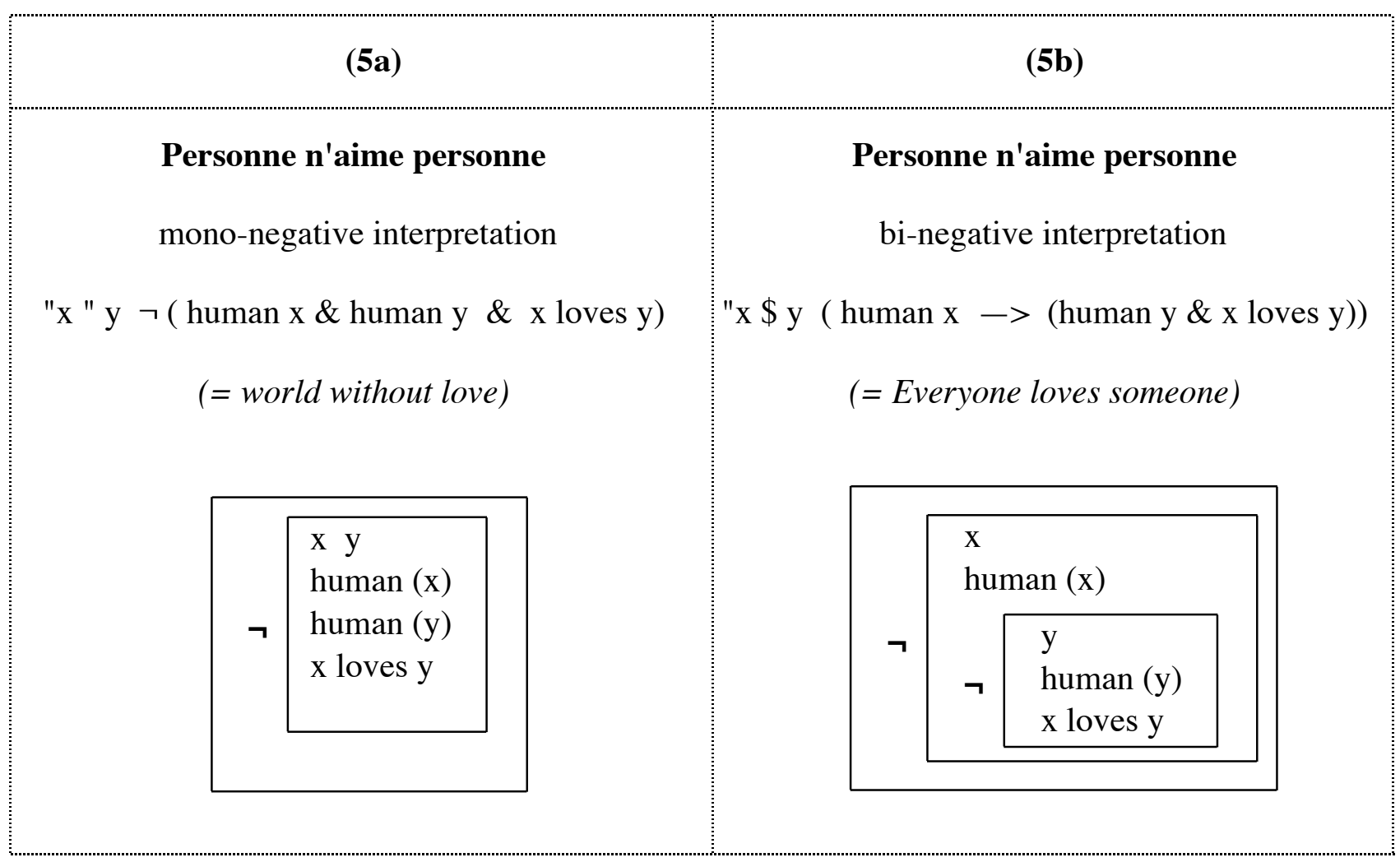

In saying that the above DRSs correctly represent the interpretations, we mean that the application of Kamp and Reyle's verification algorithm (12) to these DRSs will make correct predictions about the truth conditions of each of the interpretations.

Note that 5(a) and 5(b) are opposites, which means that the very same string of words can be used to contradict itself. We can imagine contexts in which it might happen. Suppose for instance your son tells you that he does not want to go to a party, and justify his position by saying:

(35) Pourquoi y aller puisque personne n'aime personne, dans ce groupe? [=Why should I go, since nobody loves anybody in this group?]

If you think he is wrong about that, you might object (36): 
(36) Mais c'est faux! Personne n'aime personne: Alain adore Pierre et Jeanne, tu aimes Sarah, etc...

[ =But you are wrong. Everybody loves somebody, Alain loves Peter and Jane, you love Sarah, and so on]

French native speakers are often inclined to say that the mono-negative reading 5(a) is standard, whereas the bi-negative reading $5(\mathrm{~b})$ is more difficult to get, more artificial. Usually, if you ask a speaker what a sentence like (5) means, she would immediately grasp the 5(a) reading, and very often then, she would say something like "but it can also mean that everybody loves somebody". Nevertheless, there are many cases where pragmatic or plausibility constraints select the bi-negative reading and rule out the mono-negative reading, for instance in (37):

(37) Personne n'est l'enfant de personne

[nobody-is the child of-nobody]

In as much as its is difficult to imagine a world with human beings and with no parent-child relation, only the trivial bi-negative interpretation will be selected. Nevertheless, if you are considering a restricted group of humans, say, for instance, the staff of a factory, the mononegative interpretation no parent-child relation will be available, and necessarily preferred, just because it is possible to find a factory with no parent child relation, but impossible to find a factory staff within which everyone has her parents (an infinite set since the relation is antisymmetric). A last example; if you want to say that every student has made at least one mistake in an exercise, given that the aim of an exercise is to make no mistake, the normal way of saying is (38):

(38) Aucun étudiant n'a fait aucune faute

[=No student managed to do the exercise without any mistake]

For aucun it even seems that the preferred reading is the bi-negative one, at least for the configuration: aucun $N$-V-aucun $N$.

The detailed study of the pragmatic conditions in which one reading will be preferred, or will be ruled out, is not in the scope of this paper. The only important thing for the present purpose is to observe that two opposite readings do exist for the same string of words. A correct theory should give an account for this ambiguity.

If the two readings are representations of one syntactic structure, the only plausible account for the ambiguity lies in two different processings for the lexical expressions of that structure.

The generation of the bi-negative reading 5(b) is straightforward in the present framework, once admitted that CR-neg-Q applies recursively and processes the negative quantifiers of the sentence from left to right. 
(39) Proposal 2: sentence processing for negative triggers

Update the representation using a left-right processing for lexical negatives

The generation of the bi-negative 5(b) is achieved as follows:

(40) Generation of the bi-negative reading 5(b)

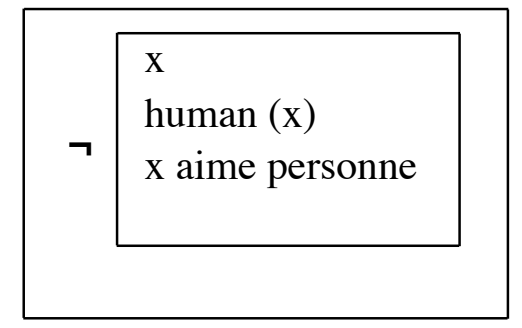

$1^{\text {rst }}$ application of CR-Neg-Q

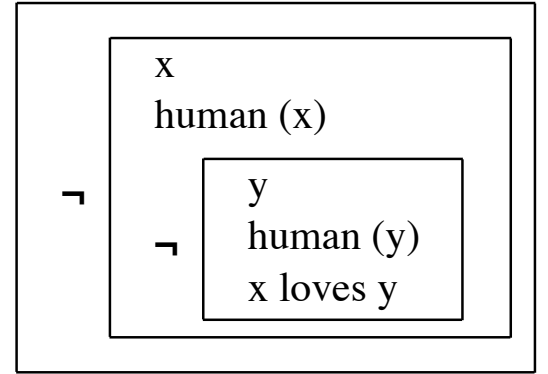

$2^{\text {nd }}$ application of CR-Neg-Q

Note that (5) cannot be interpreted with the quantifier in object position outscoping the quantifier in subject position; there is no Everyone is loved by someone interpretation (" $\mathrm{y} \$ \mathrm{x}$ ( human $\mathrm{y} \rightarrow$ (human $\mathrm{x} \& \mathrm{x}$ loves $\mathrm{y}$ )). It is precisely this interpretation which would be produced by a right-left application of CR-Neg-Q to the sentence, as illustrated in (41):

(41) Unattested processing for (5)

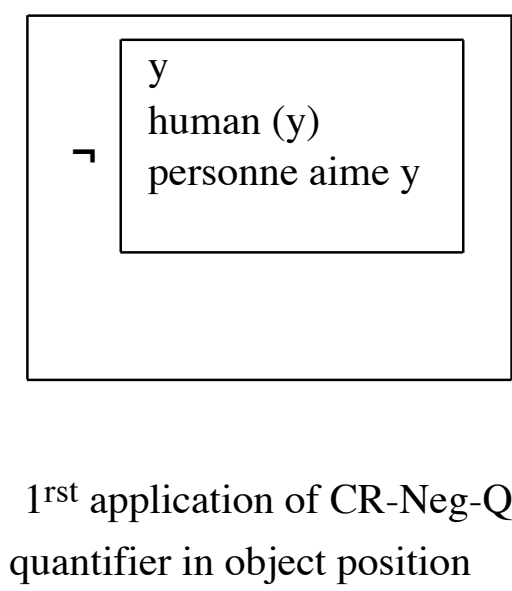

quantifier in object position

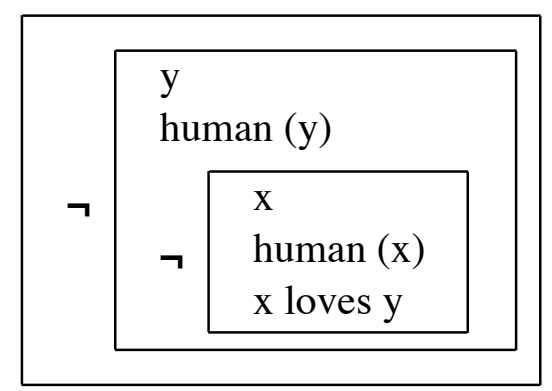

$2^{\text {nd }}$ application of CR-Neg-Q

quantifier in subject position

Once proposal 2 is admitted, (41) is ruled out. As we shall see there are many other pieces of evidence supporting proposal 2.

Proposal 1 and proposal 2 can only produce the compositional (bi-negative) reading (5)b ; in order to get the mono-negative reading 5(a) something more is needed, that will be called parasitism. 


\section{(42) Parasitism.}

If CR-Neg-Q applies to the output C of CR-Neg-Q, that is to say in the context of the negative DRS $\mathrm{K}_{\text {neg }}: \neg[\mathrm{x}[\ldots . . \mathrm{Cx} \ldots]] \mathrm{K}_{\text {neg }}$ then only the second part of CR-Neg-Q applies, the K1 of CR-Neg-Q being identified with $\mathrm{K}_{\text {neg }}$.

The metaphoric term parasitism has been chosen to capture the idea that the second occurrence of the expression, so to speak, uses a negative domain made available by a previous expression, instead of creating a new one in its own right

Figure 1 is a visual representation of a schematic construction algorithm based on proposal 1 , proposal 2 and (optional) parasitism.

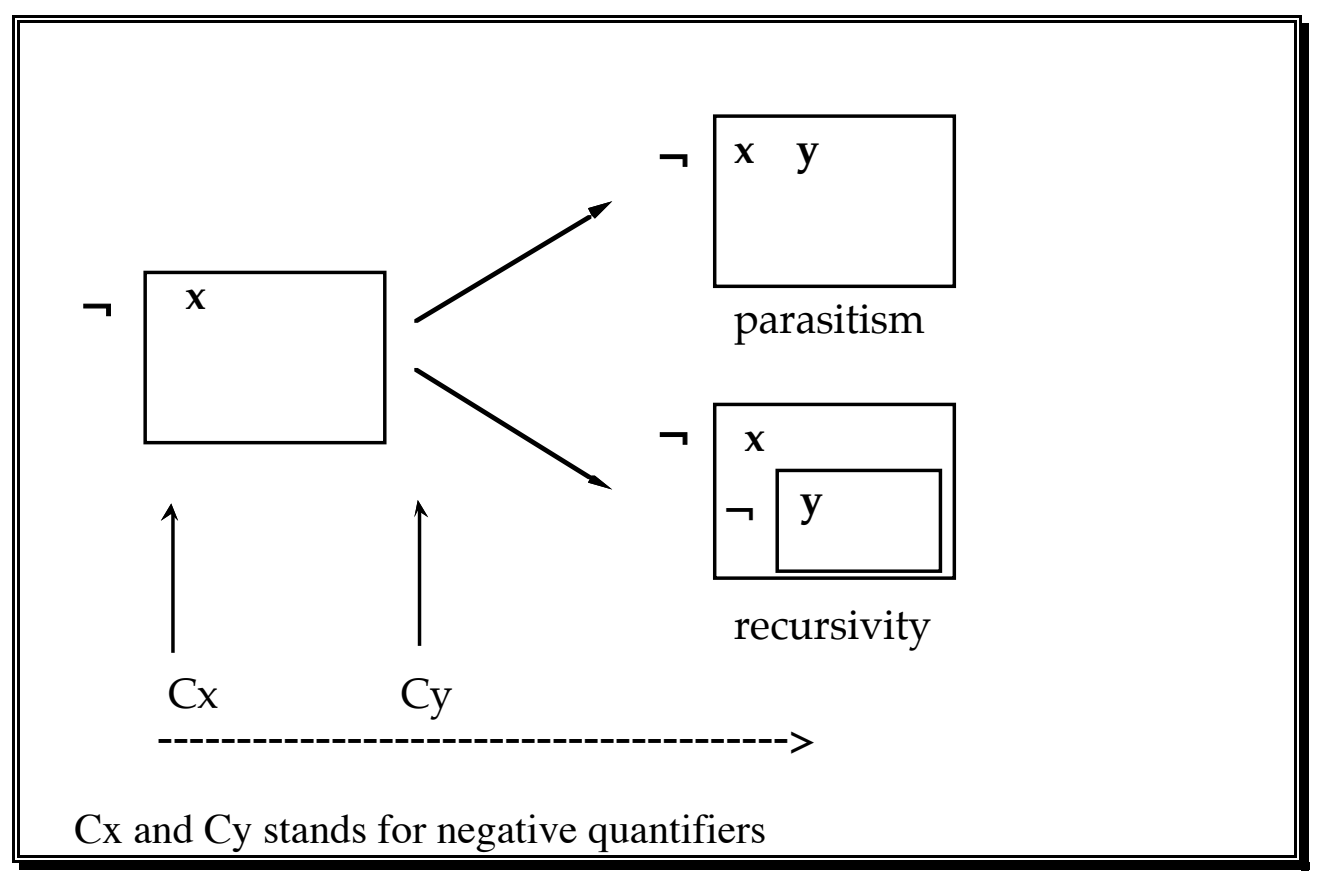

Fig 1.Processing of two negative quantifiers in Subj /Obj position

Fig 1 is a very general schema, any relevant detail of effective implementation being left aside. It is nothing but a way of getting the readings we have, and only those readings. 


\subsection{Sentences with more than two negative quantifiers}

Let us now consider the interpretation of sentences containing an arbitrary number of negative quantifiers, for instance (7) repeated for convenience in (43):

(43) Personne ne dit rien à personne

[Nobody- says- nothing-to nobody]

(43) has two interpretations, identified by (44) and (45) ${ }^{6}$.

(44) Personne ne dit rien à personne

Mono-negative interpretation

$(=$ dumb world $)$

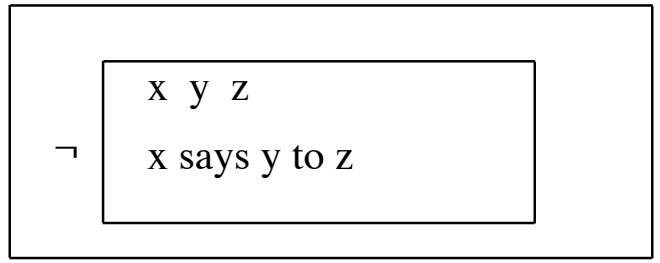

(45) Personne ne dit rien à personne

Bi-negative interpretation

(= Everybody says something to somebody)

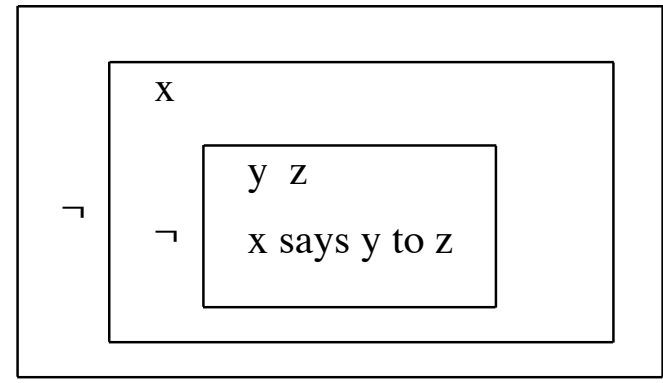

Exactly as before, the preferred reading is the mono-negative one; generally, the binegative reading seems less accessible. If one of the negative quantifiers is stressed, the binegative reading is highly favoured:

(46) Personne // ne dit rien à personne

It is much easier to get a bi-negative reading in (46) than in a neutral version.

Proposal 1 and 2 plus parasitism can generate those two readings.

6 For the sake of simplicity we don't write inside the DRSs the restrictors of the quantifiers: personne always quantifies over humans, and rien over things. 
(47) Generation of the mono-negative reading (44)

\begin{tabular}{|c|c|c|}
\hline Personne & ne dit rien & à personne \\
\hline CR Neg-Q & parasitism & parasitism \\
\hline $\begin{array}{l}\text { One negation is } \\
\text { introduced }\end{array}$ & only $\mathrm{CR}_{2}$ applies & only $\mathrm{CR}_{2}$ applies \\
\hline
\end{tabular}

(48) Generation of the bi-negative reading (45)

\begin{tabular}{|c|c|c|}
\hline Personne & ne dit rien & à personne \\
\hline CR Neg-Q & recursivity & parasitism \\
\hline $\begin{array}{l}\text { One negation is } \\
\text { introduced }\end{array}$ & $\begin{array}{l}\text { One negation is } \\
\text { introduced }\end{array}$ & only $\mathrm{CR}_{2}$ applies \\
\hline
\end{tabular}

However, it may be interesting to compare what we get with what is theoretically licensed, if recursivity and parasitism play freely. Figure 2 is a schematic representation of all the combinations that a program applying freely the two operations from left to right would produce.

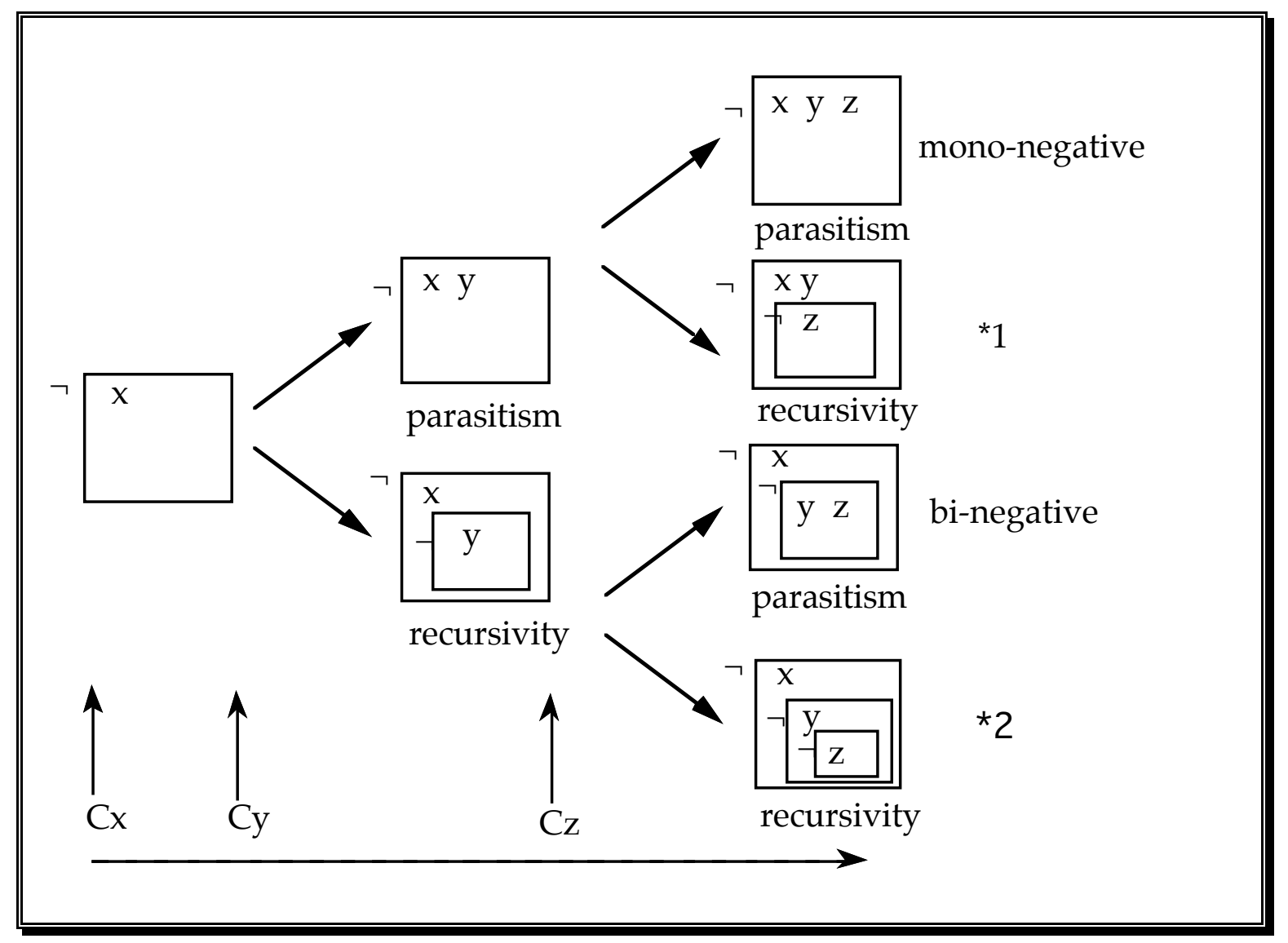

Figure 2: The set of potential representations. 
Only two out of four representations do correspond to interpretations human interpreters are able to associate to that string; they were given above in (44) and (45).

Nevertheless, the starred DRSs are well formed DRS, and their interpretation (it would be more exact to say their potential interpretation) is easily computable by the basic recursive algorithm of Kamp and Reyle.

(49) Personne ne dit rien à personne

Bi-negative interpretation $* 1$ :

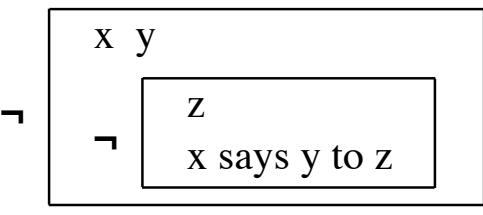

"x " y \$ z (x says y to z)

Every speech act has an addressee

(50) Personne ne dit rien à personne

Tri-negative interpretation $* 2$ :

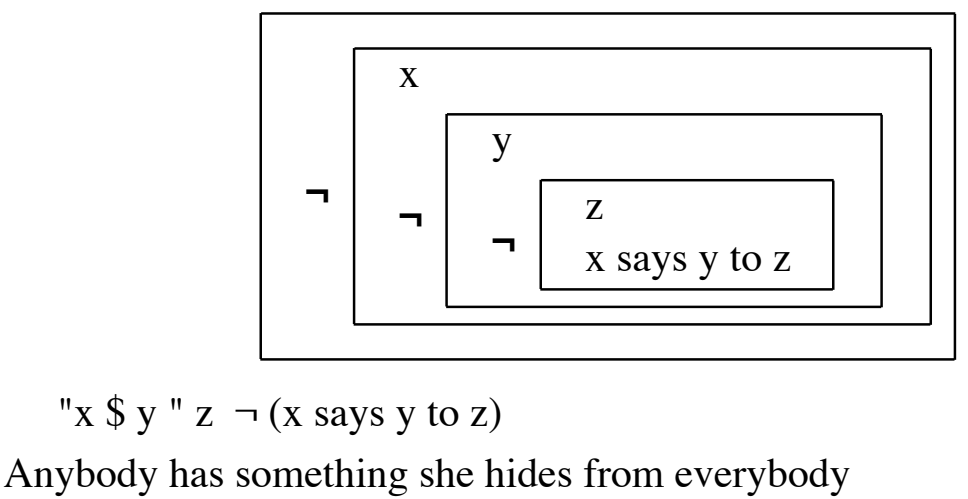

Any speaker with an exposure to formal logic can understand the paraphrases of the starred representations, and can imagine situations in which they are true; she can say how the world is when those DRSs are verified. What a speaker cannot do is to associate those representations with the string under consideration. Moreover this impossibility is strong: it is not similar to the well known situations in which complex auto-embeddings are to be processed, e.g., relative clauses, or standard auto-embeddings of negations (about which more will be said later). 
(51) I gave the girl the boy admires a book

(52) I gave (the girl ((the boy the dog bit)) admires) a book

In those so-called "performance limitations" the processing of complex embeddings may be impossible in a short time, and the structure then receives no interpretation. If more time is given to the human processor, she will get the same result as the program.

In the present case, the sentence is easy to process for a speaker, but some potential constructs $(* 1$ and $* 2)$ are completely inaccessible. Nevertheless those constructs are derived with nothing more than the basic rules which produce accessible constructs; it is not clear then whether this limitation is to be seen as a weak competence limitation (since only rules working elsewhere are concerned), or as a strong performance limitation (because it is a yes/no matter, not a matter of degree). ${ }^{7}$

At this point, the solution has two major shortcomings:

The generation mechanism which is necessary for producing existing readings is two powerful;

moreover, it is based on an ad hoc operation, parasitism, which is overtly non compositional. I would like to propose a solution to both questions, which views parasitism as a complexity regulator.

\subsection{Parasitism as a complexity regulator}

If we look at the class of possible interpretations for simple French sentences with an arbitrary number of Negative quantifiers, a simple characterization is possible: the resulting representation will have at most one negation auto-embedding, no more than one binding from outer to inner negation, and the highest negation will be introduced by the leftmost negative quantifier. What we seem to have is a limitation on the possible complexity of those structures. What we have called parasitism has the result that the complexity of the representation is kept below a threshold. Parasitism will be optional when below the threshold, and obligatory when the threshold is reached. It is thus possible to consider that parasitism behaves exactly as a complexity regulator which is defined with respect to a threshold. So we will add a third proposal to 1 and 2:

\section{(53) Proposal 3: complexity regulation of CR NEG-Q}

The application of CR Neg-Q in a clause is constrained by a threshold of complexity:

1. the maximal depth of auto-embedding is one;

2. the maximal number of bindings from outer negation is one.

Parasitism applies optionally below the threshold.

\footnotetext{
7 I am grateful to Eva Ejerhed for having pointed to me that this limitation was not unquestionably a competence limitation, which was my initial view.
} 
Parasitism must apply when the threshold is reached.

Proposal 3 is seen as a constraint on the on-line processing of negative quantifiers within a clause. It is just one among many ways of telling the story of fig 2 . More will have to be said to substantiate the claim that this constraint has something to do with complexity, although this idea does not seem a priori conter-intuitive, at least regarding (53) $)_{1}$. The case of $(53)_{2}$ is probably more controversial: in what sense the bi-negative (49), with two bindings from the outer negation, should be said more complex than the bi-negative (45), with only one of such bindings? It could be argued in that case, that although the representation itself is not more complex, the processing path is so: looking at fig.2, we can infer the maxim "once you have called parasitism, stick to it". This looks sound if parasitism is a means of limiting the complexity: once you have called a complexity regulator, it would make no sense to call a complexity increasing processing operation. ${ }^{8}$

It is worth noting that a system designed along these lines seems to produce the correct results for an arbitrary number of negative quantifiers. Consider for instance (54), which contains four negative quantifiers:

(54) Personne ne dit jamais rien à personne

[Nobody- says- never-nothing-to nobody]

(54) has only two possible representations: either parasitism is always applied, and we get a mono-negative representation, or recursivity is applied on the second quantifier, after which only parasitism applies.

The other observation worth making is that when we take this way of telling the story in terms of limitations on complexity, even the first step might seem less odd. We do have some representations with negative auto-embeddings, but the maximal depth of auto-embedding is one, so we observe a very strong limitation on complexity. It is then sound to think of the minimal auto-embedding itself as a complex structure, a threshold. Then the application of parasitism at the first step would be a natural way to keep the complexity of the structure below this threshold. Note that the empirical distinction between the preferred reading (mono-negative) and the marked one (bi-negative) is straighforwardly captured by the hypothesis, since the later one is assumed to reach the threshold for complexity.

Thus, the hypothesis that comes to mind, is that the processing of negative quantifiers is regulated by a clause-bound dynamic limitation on the complexity of representations: negative quantifiers both trigger the introduction of a negative DRS and fill its universe with a Reference Marker; they do so unless the output of both actions would cross the threshold of complexity; in those cases, only the second action is performed (what we call parasitism).

8 This view of case $* 2$ has been suggested to me by Robin Cooper (p.c.). 


\section{On the Complexity of negation auto-embedding}

The aim of this section is to substantiate the claim that the above mentioned constraint is related to the inherent complexity of some negation auto-embeddings.

\subsection{Classical double negation elimination}

The double negation law $\neg(\neg \mathrm{P})=>\mathrm{P}$ has something to do with complexity, since we can see it as a simplification rule; it is easy to state this law as: don't worry about processing too many embedded negations, just simplify; the maximal number of negation you may ever have to actually process then is in fact one. Logicians as Ramsey for instance were very reluctant about the idea that negation is a true recursive operator. Ramsey suggests that it might be an illusion, due to the fact that in natural language, negation is expressed by a discrete word, which as such, can be repeated. For Ramsey, we would have a more exact picture of what is going on for propositional negation if in order to express the negation of $\mathrm{P}$ we would choose to write, or to spell, $\mathrm{P}$ upside down; it would follow transparently then that $\neg(\neg \mathrm{P})$ is nothing but $\mathrm{P}$, and so on.

\section{(55) Natural language negatives Vs Ramsey's negatives}

\section{NL negatives}

The door is open

The door is not open

It is not true that the door is not open

It is not true that it not true that the door is not open

PL negatives

$\pi$

$\neg \pi$

$\neg \neg \pi$

$\neg \neg \neg \pi$

\section{Ramsey's negatives}

The door is open

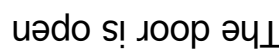

The door is open

uədo s! ı०op әчц

\section{Ramsey's negatives}
$\pi$

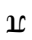
$\pi$
$\mathfrak{1}$

The processing of such sentences by humans is complex for many reasons:

1. the semantics of simple negation in itself is complex because it reverses truth values;

2. the processing of multiple negation is complex because this operation must be reiterated.

This kind of complexity is conscious for natural language users, and gives rise to well known performance limitations. Nevertheless, it is also reasonable to argue that there is no processing complexity at all, since when processing an arbitrary number of such negatives, in practice, you never have to consider more than one negation at once: when one negative is 
found, you have one negation in process, when another one is found, you have no negation in process, etc. (Cf. Ramsey). As any course book in elementary logic reminds you, all you have to check is whether the number of negatives you process is odd.

However, this kind of elimination holds for formulae like $\neg(\neg(X))$ s iff X is not bound in ()s; for instance, in a formula like $\neg(\exists \mathrm{y} \neg(\mathrm{Xy}\})$ no simple elimination is valid. It is very interesting to observe that if the analysis we proposed in (27) for negative quantifiers is correct, parasitism is optional precisely when such structures would be built, and when such structures would become more complex, then parasitism is obligatory.

\subsection{Complex negation auto-embedding}

In Kamp and Reyle (1991), a calculus is introduced for first order Discourse Representation Language. The Double Negation Reduction rule is one of Kamp and Reyle's deduction rules. If a DRS like (56) can be proved,

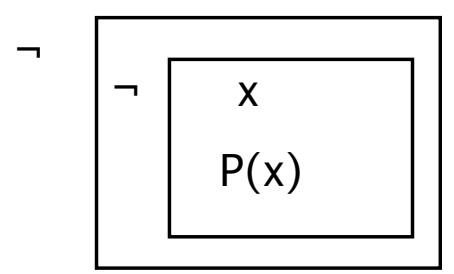

then a DRS like (57) can be:

(57)

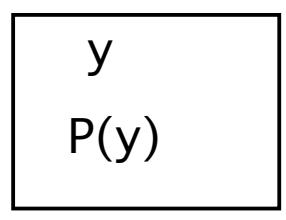

However, as observed by the authors, "when the DRS to which the outer negation applies, contains material beside the DRS to which the inner negation applies, Double Negation Elimination is more complicated" (p.16). The case considered by Kamp and Reyle (1991) has exactly the same structure as the bi-negative representation produced by the recursive application of CR-Neg-Q (see for instance (5)b above). 


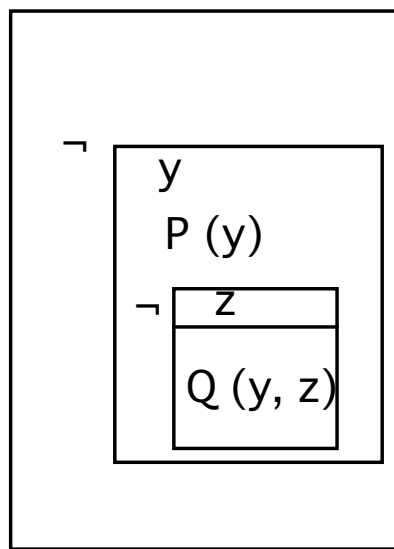

A

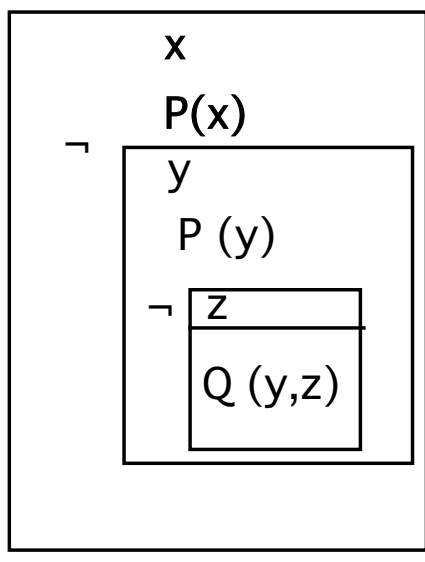

B

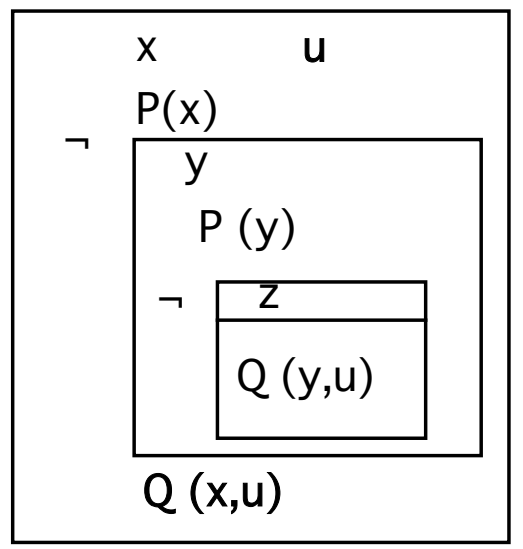

$\mathrm{C}$

fig 3. Elimination of complex negation (from Kamp and Reyle 1991)

(A) is the representation of the relevant structure in Kamp and Reyle. The outer negation has a non-empty universe (the discourse marker $y$ ) and this discourse marker is bound from the inner negation by the condition $\mathrm{Q}(\mathrm{y}, \mathrm{z})$ According to the claim of this paper, this is exactly this representation that we get from the recursive processing of two successive negative quantifiers (see for instance 5(b)). It is worth noting, that Kamp and Reyle do not consider any specific linguistic data, they just examine from a general point of view the different cases of "double negations" created by the DRT language, and the valid inference allowed by each representation.

What they claim for (A) is roughly what follows: in any Model where you can prove (A), and where moreover you can prove a second premise as illustrated in (B), then it is logically valid to infer that the conclusion highlighted in $(\mathrm{C})$ can be proved in that Model: this rule says that if $\mathrm{A}$ is true, then every time there is an individual that instantiates the outmost condition of (A), then it must be the case that there is an individual who satisfies the inner condition of (A), i.e., it says that (A) allows the same inference as the conditional statement (58):

$$
\exists x P(x)-->\exists \text { u } Q(x, u)
$$

Remaining close to the DRT formalism the negation elimination would look like (59): 
(59) Double negation elimination in bi-negatives

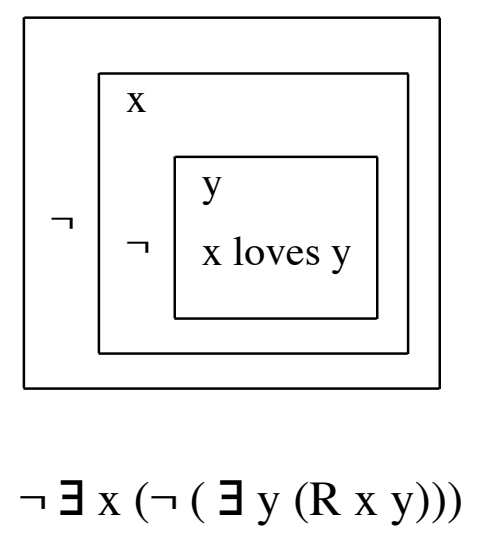

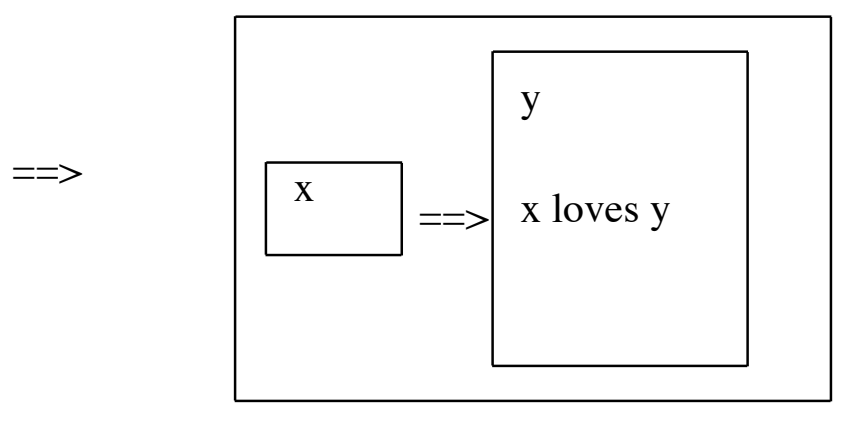

$\forall \mathrm{x} \exists \mathrm{y}(\mathrm{R} \times \mathrm{y})$

To say that Double Negation Elimination is "more complicated" in that case, as do the authors, is an understatement: in fact, what we have is not a simplification via double negation elimination, but actually a reformulation of the original negative auto-embedding by means of inference rules.

In the simple case of auto-embedding negation (Cf. 56-57), you actually get an equivalent representation just by wiping out the negations (see the move from 56 to 57 supra). But in (59) what you must achieve in order to eliminate negations and get an equivalent representation is a complete reformulation using different connectives. It is for instance not so difficult to consider the simplification in the first case as the result of an on-line processing, something like: I am processing a negation, I come across another one, well, I give up both... But in the case of (59), such an on-line processing leads to much more complications. We might suggest the following: this interpretation of the sentence does not seem to be spontaneous, it requires some sort of afterthought, because it is not directly accessible, but only after negation elimination, via a conditional representation like in (59). In this very strong speculative version of the hypothesis, bi-negatives could not be processed, and would only be reformulated.

As for tri-negatives, negation elimination would look like (60): 
(60) Negation elimination in tri-negatives

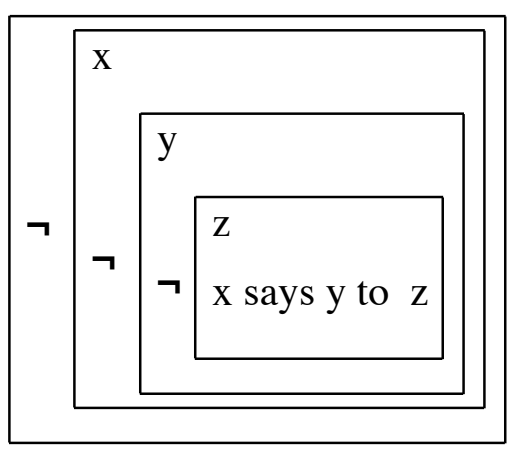

$\neg(\exists \mathrm{x}(\neg(\exists \mathrm{y}(\neg(\exists \mathrm{z}(\mathrm{Rxyz}))))))$

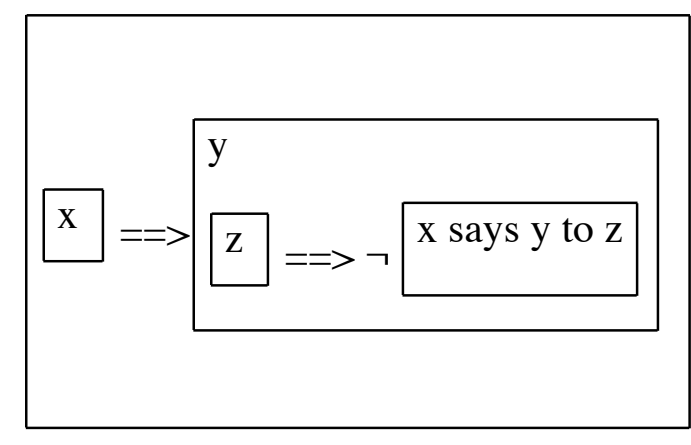

$\forall \mathrm{x} \exists \mathrm{y} \forall \mathrm{z} \neg(\mathrm{R} x \mathrm{y} \mathrm{z})$

In this case, we keep one negation, and we get a very complex logical structure which seems difficult to compute on-line.

Maybe we have now a better understanding of what is exactly the specific complexity problem for this kind of negative auto-embedding: the problem is precisely that the universe of the outer negation is bound by a condition of the inner negation, which rules out any online simplification. The depth of embedding will then make the representation more and more complex to process.

Hence, it is worth examining the behaviour of the two kinds of negatives distinguished in (24$25)$, negative triggers and negative quantifiers, when they are in the same sentence. We will then be able to sketch a general typology of negative embeddings and say in exactly which conditions the kind of derogation to compositionality called here parasitism takes place.

\subsection{Multiple negation with trigger and quantifiers}

If a sentence containing both a negative trigger pas and a universe-negative is processed, the representation cannot be mono-negative, which means that no parasitism can take place from a negation introduced by a negative quantifier to a negation introduced by a negative trigger. They are, as it were, processed each on their own side.

When the negative quantifier is in subject position, the sentence has a reduced degree of acceptability, as in (60):

(61) (?) Personne ne m'aime pas

[Nobody-don't-me-love]

The acceptability of the sentence improves if the negative quantifier follows the negative 
trigger as in (62):

$$
\begin{aligned}
& \text { Je n'aime pas personne } \\
& \text { [I-don't-love-nobody] }
\end{aligned}
$$

Both sentences are used mainly as echo-sentences, and both have only a bi-negative interpretation. Moreover, the only interpretation available is produced by a strict left-right processing of the sentence:

(63) Correct representation of (62)

Je n'aime pas personne

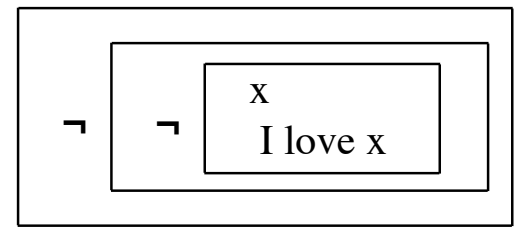

(64) Incorrect representation of (62)

Je n'aime pas personne

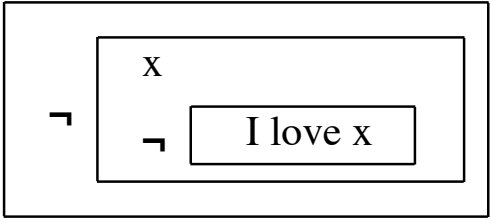

Kamp and Reyle's algorithm tells us that (63) is true iff there is at least one person $\mathrm{x}$ such that I love $\mathrm{x}$. This is the correct interpretation of the sentence, and it will be obtained if we process the negative trigger pas first, building a negative DRS, and then process the negative quantifier in the scope of this higher DRS. If we process the universe-negative first, and then the negative, we get (64) whose meaning according to the algorithm (12) is equivalent to: for every $\mathrm{x}, \mathrm{I}$ love $\mathrm{x}$.

A few comments may be in order about this case. Firstly it seems to contradict any attempt to see expressions like personne, rien, etc. in multiple negation as negative polarity items (Cf. supra 1.2.1). The context in (62) is a very typical licenser for polarity item, but the only interpretation admissible for personne in this context is a true negative interpretation. This is the more interesting point, since personne, rien, jamais, actually can be used as polarity items in some other contexts. Although undoubtedly attested, this use of some negative quantifiers as Polarity Sensitive Items is not without constraints in French:

1 - This use is very rare, and much more rarer in the spoken language. ${ }^{9}$

\footnotetext{
${ }^{9}$ It actually means that the use of negative quantifiers as PSI is mainly licensed in those dialects of French in which $n e$ is almost obligatorily present in negative sentences. One might suspect a causal relation between these two facts.
} 
2- The most easily accepted item in this use is jamais, and if jamais is present, it is easier to use another negative quantifier as PI in the sentence.

3 - Some negative quantifiers cannot be used as PSI in the absence of jamais, e.g., aucun N.

On the matter of negative quantifiers and corresponding polarity items, French might be opposed to English very roughly as follows: both French and English have negative quantifiers, but English has distinct polarity items, whereas in French, some lexical items can be either negative quantifiers or polarity sensitive items; those lexical items in French, although licensed by some polarity contexts, are not licensed by a clause mate negation trigger.

Consider for instance (65) and (66):

(65) Je ne crois pas que personne ait jamais dit cela [I-don't think that-nobody-has-never-said-that]

(66) J'y arriverai, si personne y arrive jamais [I will succeed if-nobody-succeeds-never]

In these contexts, personne, and jamais have no negative meaning at all, their English translation will use polarity items, and they can be replaced in French by standard indefinites without changing the interpretation as is $\left(65^{\prime}\right)$ and $\left(66^{\prime}\right)$ :

$\left(65^{\prime}\right)$ Je ne crois pas que quelqu'un ait dit cela un jour

(66') J'y arriverai, si quelqu'un y arrive un jour

So, if one is inclined to analyse personne as a polarity item in personne n'aime personne, one will have to admit that personne in subject position, but not the standard negation pas, licenses a polarity item interpretation of personne in object position, which seems hopelessly ad hoc. Many other arguments are against the idea that the second occurrence of a negative quantifier is a polarity item. In French, the polarity sensitive interpretation is only available if ne is not licensed: in (65) and (66) above, if ne occurs in the same clause as personne andjamais, then the negative interpretation of those items is restored. In the multiple negation case, ne is licensed. So the polarity sensitive theory for multiple negation sentences would lead to give up an important generalization about the form-meaning mapping in French. Moreover, as Muller (1987) has shown, some languages have no independent use of negative quantifiers as polarity items, whereas they have mono-negatives readings corresponding to the occurrence of more that one negative.

Another interesting point about (62) is that the linear order of negatives gives the only attested scope hierarchy, which agrees with proposal 2 above. For sentence (61), if accepted, for instance as a denial of $X$ ne m'aime pas, the only correct representation is (67): 
(67) Correct representation of (61)

(?) Personne ne m'aime pas

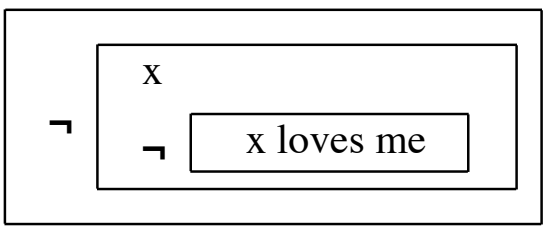

The meaning of (67) is: there is no $x$ that does not love me. The other scope hierarchy would mean: it is false that there is no $\mathrm{x}$ such that $\mathrm{x}$ loves me; $(61)$ cannot be interpreted this way. Again, the correct result is obtained iff the triggers are processed following their linear order. Evidence supporting these observations comes from sentences with more than two negative quantifiers like (68):

(68) Je ne dis pas rien a personne

[I-don't-say-nothing-to nobody]

This sentence can only mean: I say at least one thing to at least one person. So the only correct representation in the present framework is (69):

(69) Correct representation of (68)

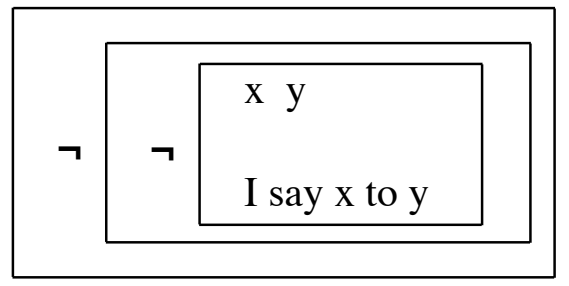

Three things are of special interest in this respect:

1) again, only a left-right processing gives the correct representation.

2) again, there is no parasitism from the negative quantifier to the negation introduced by a previous negative. They are independent.

3) much more interesting: parasitism necessarily applies from negative quantifier 2 (personne) to negative quantifier 1 (rien), although we are only at the second step of the processing of negative quantifiers.

Had recursivity applied, the resulting representation for (68) would have been (70): 
(70) Maximally recursive (incorrect) representation of (68)

(68) Je ne dis pas rien à personne

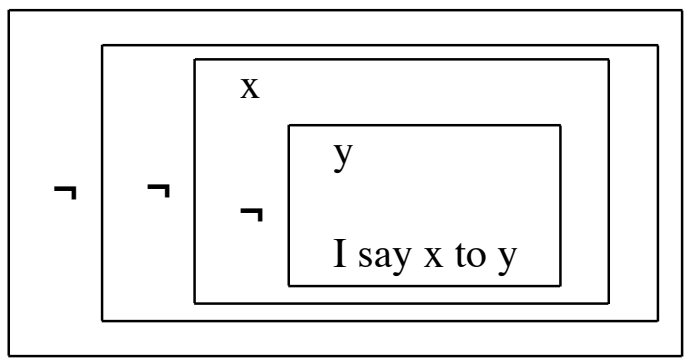

What (70) means is: there is at least one $\mathrm{x}$ such that, for every $\mathrm{y}, \mathrm{I}$ do not say $\mathrm{x}$ to $\mathrm{y}$. This is not a correct representation for (68).

This seems to mean that the regulation constraint on complexity is sensitive to the higher negation. The construction algorithm must process in this order:

\begin{tabular}{|c|c|c|}
\hline je ne dis pas & rien & à personne \\
\hline Trigger & Negative quantifier 1 & Negative quantifier 2 \\
\hline CR Neg-Q & recursivity & parasitism \\
\hline $\begin{array}{l}\text { One negation is } \\
\text { introduced }\end{array}$ & $\begin{array}{l}\text { One negation is } \\
\text { introduced }\end{array}$ & only $\mathrm{CR}_{2}$ applies \\
\hline
\end{tabular}

When processing Neg-Q 1, the algorithm has already a negation in process (from the previous processing of the negative trigger); it is instructed by Neg-Q 1 to introduce another negation and to fill the universe of this negation: things then work as if by so doing the threshold of complexity were already reached; consequently, no more negations can be introduced, and Neg-Q 2 will parasite the most recently introduced negation (Neg-Q 1).

Remember that CR Neg-Q in French can only parasite a negative quantifier; in other words, if a regulation mechanism is postulated, the effects of this mechanism can only show from a negative quantifier to a negative quantifier. Nevertheless, as it appears from (70), a negative can have some effects, since its processing will count as a complication of the current structure .

Such a difference between those two kinds of negatives is not ignored by linguists. The French linguist Tesniere (1959) distinguished between two kinds of negatives: "négatifs imperméables", doing their negative job in any circumstance, and "négatifs perméables" which can lose their negative force in some contexts. In this sense French negative quantifiers are perméables, while French negative trigger is imperméable.

Classical negation elimination in auto-embeddings can only take place if the outer universe is 
empty. Consider (70) and (71), involving the negative trigger pas and the standard indefinite un $N$ :

(71) John n'a pas accepté un étudiant

[John-did not-accept-a student]

(72) Il n'est pas vrai que John n'a pas accepté un étudiant

[It is not true that John did not accept a student]

For the sake of simplicity, we will assume that it is not the case that $P$, is represented as not $P$. (71) will have two distinct representations: in (73)a the indefinite is interpreted at the top level, in (73)b, it is interpreted in the universe of the negative DRS.

(73) Representations of (71)

John n'a pas accepté un etudiant

x y
John $(\mathrm{x})$
student $(\mathrm{y})$
$\neg \quad \mathrm{x}$ accepted $\mathrm{y}$

(73)a

Wide scope indefinite

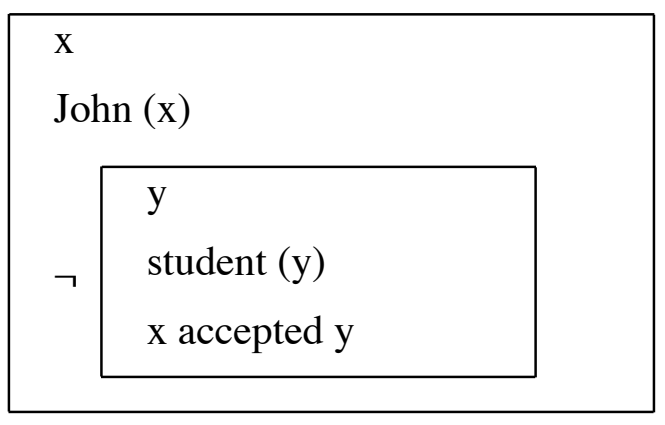

(73)b

Narrow scope indefinite

For (72) we will thus expect at least two representations:

(74) Representations of (72)

Il n'est pas vrai que John n'a pas accepté un étudiant

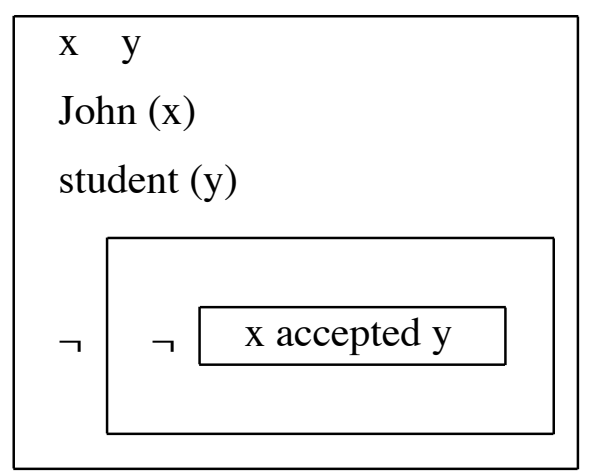

(74)a

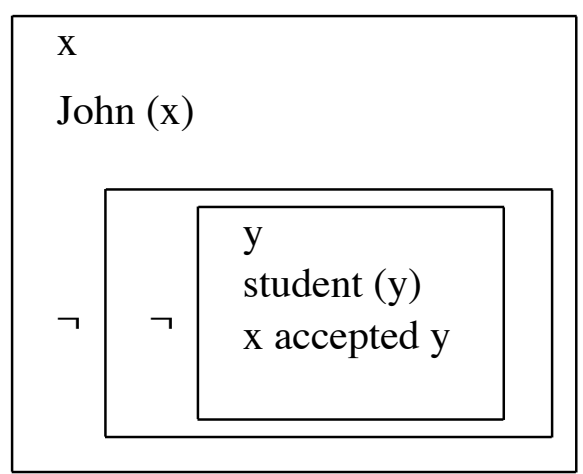

(74)b 
Negation elimination is not prohibited in that particular case, since there is no binding from outer to inner negation (the relevant fact is thus the emptiness of the outer universe). As suggested in (54)/(55) above, negation elimination will trigger a "merging"10 between the inner material (the material of the inner DRS) and the outer DRS (in (74), the top-level DRS): the discourse referents go up to the outer DRS, and the set of conditions in the inner DRS is included in the set of conditions of the outer DRS.

If we eliminate the negations we get the same deduction for the two DRSs:

(75) Representation of (74)a and (74)b after double negation elimination

\begin{tabular}{|l|}
\hline $\mathrm{x} y$ \\
John $(\mathrm{x})$ \\
student $(\mathrm{y})$ \\
$\mathrm{x}$ accepted y \\
\hline
\end{tabular}

This consequence is correct, since the two sentences are true exactly in the same worlds, i.e., iff there is at least one student y such that John accepted y.

Now there is another virtual representation we should have considered for the sentence (72), namely an interpretation of the indefinite in-between (74)a and (74)b, i.e. in the universe of the outer negation, as in (76):

(76) Potential "medium scope" interpretation of the indefinite

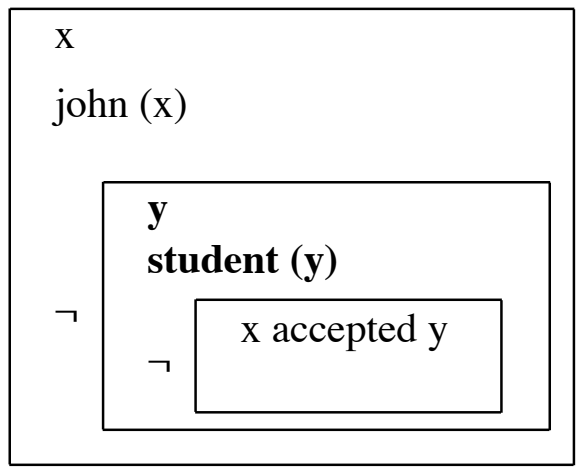

According to the verification algorithm, (76) means that John accepted every student; but although this virtual representation does not seem to be ruled out by any known principle, this

\footnotetext{
10 See the "Merge" operation in Zeevat (1989).
} 
is not a correct interpretation for the sentence (76): now if we look at (76) we can see that this interpretation of the indefinite would precisely create this kind of complex structure with binding from outer to inner negation, the kind of structure which in our hypothesis is beyond the threshold of complexity.

The interesting thing about these complexity constraints in (72) is that they do not concern negative quantifiers, but two independent expressions, namely negative triggers and indefinites. It can be taken then as an independent confirmation of the inherent complexity of this kind of negative auto-embedding.

\subsection{No-parasitism cases}

This sections provides some empirical evidence supporting the complexity analysis. Given that there are two potential interpretations for any multiple negation sentence involving negative quantifiers, we can try to look at contexts where one of them is ruled out.

The bi-negative interpretation is seen as a threshold and thus inherently exposed to be ruled out. It is thus difficult to use those cases to prove anything.

The bi-negative interpretation is ruled out if the subject is not a negative quantifier, and if the negative quantifiers are arguments:

(77) Marie ne dit rien à personne

[Mary-do not-say-nothing-to nobody]

This sentence can only mean than Mary is dumb, or discreet; there is no interpretation such as: Mary says everything to somebody. With the negative quantifier jamais, the ambiguity is restored;

(78) Marie ne dit jamais rien

[Marie-says-never-nothing]

(78) can mean that Mary says always something.

I just mention this fact, for which I have no explanation, and give now some interesting noparasitism cases.

\section{Stress.}

It has been previously noted that a strong stress on the first negative quantifier tends to rule out the mono-negative interpretation:

(79) Personne // n'aime personne

[= Everybody loves somebody]

This is true also, and maybe even more so if the second occurrence is heavily stressed: 
(80) Personne n'aime // personne

[= Everybody loves somebody]

\section{Question/answer.}

The following question/answer succession has only one interpretation:

$$
\begin{aligned}
& \text { Q . Qui n'a rien fait? } \\
& \text { R. Personne } \\
& \text { [ = Everybody has done something] }
\end{aligned}
$$

Although, the sentence (82) has two readings.

(82) Personne n'a rien fait

$$
\begin{aligned}
& \text { [= Everybody has done something] } \\
& \text { [= Nobody has done anything] }
\end{aligned}
$$

Moreover there is a clear contrast betweeen (81) and (82); in (82), as it was previuously mentioned for (5), the preferred reading is the mono-negative one; in (81), this reading is ruled out. Again, as for a stressed quantifier in (79-80), the interpretation that is ruled out is the mono-negative interpretation, i.e., the interpretation that requires an application of the limitation mechanism (parasitism).

It is straightforward to account for that, once admitted that the constraint is a processing constraint, i.e. a constraint on what you can do within a processing unit. Suppose that stress triggers a focus/topic partition. Both focus/topic and question/answer association suppose some sort of a two steps, or two parts processing ${ }^{11}$ : each part has to be processed in its own right. If this is so, in each part there is one negative to process, and as a consequence, the representation of the whole construction will have one negation per negative, hence cannot be mono-negative. It must be also noticed that the negative interpretation of negative quantifiers when they are used in isolation in answer to questions supports the claim that their inherent meaning is negative.

\section{Relative clauses.}

In French, some negative quantifiers can be the antecedent of a relative clause containing a negative quantifier:

(83) Jean ne connaît aucun adulte qui ne lise aucune bande dessinée

$$
\text { [= Every adult that John knows reads some comic strip] }
$$

Although (83) contains two negative quantifiers, it is not ambiguous, as sentence (84)

\footnotetext{
11 This analysis suggestsInteresting issues about stress and Questions/answers which are beyond the scope of this papers.
} 
underlying the relative clause would be:

(84) Aucun adulte ne lit aucune bande dessinée

[=Every adult reads at least one comic strip]

[=There is no adult reader of comic strips]

Again, the missing interpretation is the mono-negative one; one might suppose that the antecedent of the relative clause and the relative clause itself are two different processing units; each of them thus introduces a negation, and there is no regulation by parasitism as in the simple sentence case. This makes sense since the hypothesis is about a clausal complexity regulation.

Consider now relative clauses with two negative quantifiers, one of which is the antecedent of the relative pronoun, as in (85):

(85) Je ne connais aucun roman dans lequel personne n'aime personne

[I know-no novel-where-nobody-loves-nobody]

I think that the only possible interpretation of (85) is (86):

(86) Only correct paraphrase of (85):

(=In every novel I know, there is love)

To get this interpretation in the now usual way, we must assume that the relative clause as a whole is mono-negative, i.e., that parasitism must occur between the third quantifier and the second one. It seems to be the same situation as in the Je ne dis pas rien à personne case (cf. (67) above). No parasitism can occur from the second occurrence to the first one. In a case like (85), I assume that it is so because we have two different clauses. Nevertheless, the first occurrence counts for the complexity of the whole structure. Consequently, the third occurrence of the negative quantifier must parasite the second one, although any parasitim is prohibited from one clause to one another, namely from the second quantifier to the first one. ${ }^{12}$

The only correct representation of (85) is thus as in (87):

12 This case would deserve a more careful inspection, since it seems to suggest that the antecedent of the relative clause is not considered as a part of the domain relevant for parasitism inside the relative clause. 
(87) Correct representation of (85):

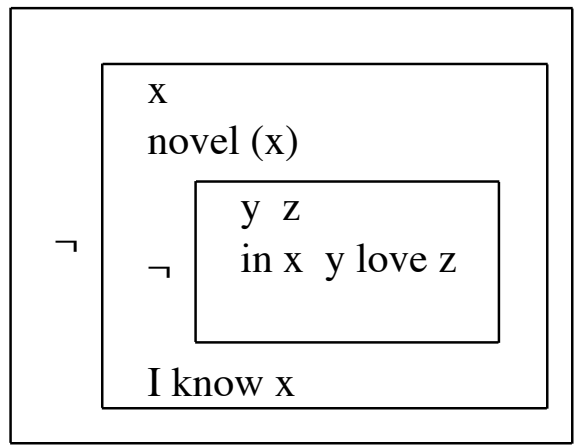

\section{Other operators on the first negative:}

If the adverb presque [almost] is adjoined to the first occurrence of a negative quantifier, we get the following interpretations:

(88) Personne n'a vu aucun film de Bresson

[Nobody-has seen-no film by Bresson]

$$
\text { Mono or bi-negative }
$$

(89) Presque personne n'a vu aucun film de Bresson

[Almost-nobody-has seen-no film by Bresson]

$$
\text { Bi-negative only (?) }
$$

(90) Presque personne n'a rien mangé hier soir

[Almost-nobody-has eaten-nothing-yesterday]

$$
\text { Bi-negative only (?) }
$$

(91) Presque personne n'est jamais venu

[Almost-nobody-never-came]

$$
\text { Bi negative only }
$$

(92) Personne n'a presque rien mangé

[Nobody-eaten-almost-nothing-]

Bi negative only

So we observe a strong tendency to avoid parasitism if the first negative quantifier is in the scope of a specific operator. What could be suggested tentatively in this case is that parasitism is rules out since it would lead to interpreting the second negation in the scope of an operator which has only the first quantifier in its scope. 


\section{Conclusion and perspective for further research}

It is commonly assumed that auto-embeddings are difficult to process, and it is well known that processing structures with embedded negations is complex.

Considering a particular natural language, this paper has tried to substantiate the claim that multiple negation sentences in this language can be explained on the basis of two independent assumptions:

1. The complexity you can achieve in processing a certain kind of negation auto-embedding is constrained by a threshold.

2. In the language considered, the limitation is done by parasitism, i.e. by downgrading negative quantifiers (negation+indefinite) to indefinites.

The validity of the assumption for a particular language has been tested in this paper against some data, but a deeper inspection should be done.

It is likely that the content of the hypothesis requires a closer inspection as well. Firstly it seems that the two parts have a different status. (1) is a candidate for a generalization across natural languages on the form-meaning relationship. The hypothesis would claim that no natural language can process more that two negative expressions building the kind of representation discussed in this paper. It must be recalled here that the lexical negation enclosed in verbs like dislike does not seem to have any relevance for the constraint under consideration. The hypothesis is thus about the processing of lexical triggers in a restricted space (the clause); the kind of negative information enclosed in lexical items like dislike does not seem to be relevant for this constraint. ${ }^{13}$

If we can find enough data supporting this hypothesis, further speculation will be useful as to whether this is a constraint specific to negation or a type of constraint relevant in other areas. (2) is a more specific hypothesis on the way in which a particular language manages to be in accordance with this constraint, or on what this particular constraint licenses in this language. Note that the hypothesis is flexible. The notion of threshold allows some variations, and the notion of parasitism is not assumed to be general; the constraint (1) can be satisfied by other means, for instance by grammatical co-occurrence prohibition and the use of polarity items. Moreover parasitism can be parametrised. French illustrates a case of weak selective parasitism: the representation of a clause can contain one negative auto-embedding, and there is no parasitism from a negative quantifier to a negative trigger. Consider now an hypothetical dialect of English within which I don't like nobody would only mean [I don't like anybody] and Nobody doesn't like me would only mean [Nobody likes me]: this dialect would likely be a case of strong generalized parasitism: no auto-embedding is licensed in a clause, and once a negation has been introduced, any other potentially negative expression

\footnotetext{
13 We have assumed all over this paper that it is sound to work with a concept of representation such that don't like has a negative representation, while dislike has not a negative representation.
} 
looses its negative force.

According to the "compositionality problem" for multiple negation this hypothesis gives the following answers. There is a derogation to compositionality for multiple negation in languages like French, and this derogation is to some extent controlled by a global constraint on the complexity of processible structures. Note that the operation called "parasitism"is not exactly any operation: it concerns a lexical expression with a two-steps meaning (builderfiller, negation+indefinite) and parasitism might be seen as a structured operation between the meaning of a lexical expression and its context. Parasitism amounts to "skipping" a part of the meaning (the "building of a context" part), exactly in the situation where an identical context has been already created by processing a similar expression. Moreover, the licenser-trigger of this derogation to compositionality contains the interpretation of the result; we thus have a derogation to compositionality, but the final interpretation is perfectly determined by the constraint which licenses it (we know that we will have one, at most two negations per clause).

Here is a very simplified presentation of the intuitive content of the hypothesis: suppose you have some terms expressing negation which can appear in different positions of a simple sentence (this is widespread in natural languages precisely for negative quantifiers); suppose moreover that you cannot process more than two such negations in a simple sentence. Then what can you do? You can avoid the co-occurrence; but you can also, so to speak, ignore the co-occurence.

Consider for the sake of comparison a calculator which can process only two numbers at once, but which takes as physical input a magnetic card which can contain an arbitrary sequence of numbers: usually you will present the calculator with a card containing only two numbers, but if you give it more, in a certain sense, it is harmless: the calculator will process the first two and ignore the rest. Let us discuss a little bit this comparison. The hypothesis of a limited calculator assumed in this paper is a way of explaining why the potentially negative expressions are "harmless". It accounts for the fact that you can put negatives everywhere, without having as many negations, and for the fact that you can use negatives as polarity items in the considered contexts.

The relationship between such a use of down-graded negatives and the use of true polarity items should be made more explicit. Some languages use polarity items (e.g. English any) instead of down-graded negatives (e.g. French personne). In French too, one can find uses of polarity items very close to the use of down-graded negative quantifiers: 


$$
\begin{aligned}
& \text { Personne n'a dit un mot } \\
& \quad \text { [nobody-said-a single word] } \\
& \text { Personne n'a rien dit } \\
& \quad \text { [nobody-said-nothing] }
\end{aligned}
$$

\begin{tabular}{|c|c|c|c|}
\hline & licenser & landing site & meaning \\
\hline indefinites & none & not fixed & indefinite \\
\hline NPI & negation & licenser's scope & indefinite \\
\hline
\end{tabular}

Note that there is a very strong connection between indefinites, polarity items and negative quantifiers:

In French for instance, negative triggers and most negative quantifiers come from true indefinites; they were then used as negative polarity items in association with the negative ne, and finally as negative expressions by themselves (hence the optional status of $n e$ ). ${ }^{14}$ It is very interesting to note that the negative meaning for French negative quantifiers has been so to speak "inherited" from contextual licensing. The relationship of this meaning to the meaning of the expression may for that reason be more easily defeasible in context. We can see then that negative quantifiers and negative polarity items can be very close categories, and that expressions can move from one category to another. It has been observed in the literature that many languages do not have specific expressions with the role of polarity items as exemplified by English. As far as multiple negation is concerned, our hypothesis would tell why negative quantifiers can do the job.

This kind of hypothesis does not explain at all why natural languages tend systematically to put numbers on the card that won't be calculated. But is there anything special to explain about that?

Consider this last example. The following French sentences are true in exactly the same situations:

(94) Personne ne mange

[Nobody-eats]

(95) Personne ne mange rien

[Nobody-eats-nothing]

In (94) the argument is not instantiated, while in (95) it is instantiated by a negative quantifier. This instantiation of the argument does not make a great difference, except for the fact that (95) is ambiguous (between a mono and a bi-negative reading). Nevertheless, in many cases, the instantiation of the argument makes a difference.

\footnotetext{
${ }^{14}$ Such a process is often called the "Jespersen cycle" from Jespersen (1917:4).
} 
(96) Personne n'écrit rien

[Nobody-writes-nothing]

(97) Personne n'écrit rien à personne

[Nobody-writes-nothing-to nobody]

In (97) the instantiation of the complement selects the interpretation to send messages to someone, while in (96), it is more likely that the verb just mean to write something.

\section{(98) Jean ne lit rien}

[Jean-reads-nothing]

In a sentence like (98), the time location is not fixed unambiguously; the sentence can be taken to be true now, or to be true in general. If the negative temporal expression is used, we will get a reference marker in the scope of the negation, and the general interpretation is selected.

(99) Jean ne lit jamais rien

[Jean-reads-never-nothing]

I think that the notion of concord/agreement is not very appropriate; the instantiation of the argument is most often just a way of getting something that would not be achieved without it, namely the unambiguous interpretation of an indefinite in the scope of a negation. So what might be taken as a mechanical rule is actually meaningful. 


\section{REFERENCES}

Barker, C., Dowty, D. (1992) Proceedings of Second Conference on Semantics and Linguistic Theory, Ohio State Working Papers in Linguistics.

Corblin, F. (1992) "Le traitement des complexes négatifs en DRT", in Actes du colloque ECCOS"92., Orsay, France, pp.157-175.

Fauconnier, G. (1975) "Pragmatic Scales and Logical Structures", in Linguistic Inquiry VI 3, pp.353-375.

Fauconnier, G. (1977) "Polarité syntaxique et sémantique", in Linguisticae Investigationes I 1, pp.1-38.

Gabbay, D, Kempson, R. (1992) Natural-Language Content and Information Flow," ms.

Gazdar, G.

Groenendijk, J., Jansen, T., Stokhof, M. (1984) Truth interpretation and information, Dordrecht, Foris.

Groenendijk, J., Stokhof, M. (1991) "Dynamic Predicate Logic", in Linguistics and Philosophy, pp.39-101.

Haegeman, L., Zanuttini, R.

Heim, I. (1982) The semantics of definite and indefinite and indefiite noun phrases

Hobbs, J.R., Shieber, S.M. (1987) "An Algorithm for Generating Quantifier Scopings", in Computational Linguistics, 13, pp.47-63.

Jespersen, O. (1917) Negation in English and Other Languages, A.F. Host.

Kadmom, N., Landman, F. (1993) "Any", Linguistics and Philophy, vol 16,3, pp. 353-422

Kamp, H. (1981) "A theory of truth and semantic representation", in GROENENDIJK 1984, pp.1-41.

Kamp, H. (1990) " Comments on J. Groenendijk and M.Stokhof: Dynamic Predicate Logic", DYNA deliverable R2.1.A

Kamp, H, Reyle, U. (1991) A Calculus for First Order Discourse Representation Structure , Arbeitspapiere des Sonderforchungsbereichs 34

Kamp, H, Reyle, U. (1993) From Discourse to Logic, Kluwer.

Laka, I. (1990) Negation in Syntax: on the nature of functional categories and projections, Ph.D, M.I.T.

Ladusaw, W.A. (1992) "Expressing Negation", in BARKER 1992.

Linebarger, M. (1980) The grammar of Negative Polarity, Ph,D., M.I.T..

May, R. (1985) Logical form. Its structure and derivation, MIT press.

May, R. (1989) "Interpreting Logical Form", in Linguistics and Philosophy, 12,4, pp.387 437.

Muller, C. (1987) La négation en français: syntaxe, sémantique et éléments de 
comparaison avec les autres langues romanes, Thèse d"Etat, Paris 7.

Progovac (1993) "Negative Polarity, Entailment and Binding", Linguistics and Philosophy $16,149-180$,

Ramsey, F.P. (1931) The Foundations of Mathematics and Other Logical Essays, R.B. Braithwaite, ed., Routledge \& Kegan Paul.

Ramsey, F.P. (1990) Philosophical Papers, D.H. Mellor, ed., Cambridge University Press.

Szabolcsi, A., Zwarts, F. (1991) Unbounded Dependencies and Algebraic Semantics, Lectures Notes, Saarbrücken.

Van Benthem, J. (1989) "Polyadic Quantifier", in Linguistics and Philosophy, 12,4, pp.437465.

Zanutrini, R. (1991) Syntactic Properties of Sentential Negation. A Comparative Study of Romance Languages. Ph.D. Univesrsity of Pensylvania.

Zeevat, H. (1989) "A Compositional Approach to Discourse Representation Theory", in Linguistics and Philosophy, Vol 12, 1, pp.95-131.

Zwarts, F. (1992) The syntax and semantics of negative polarity, ms. Rijksuniversiteit, Groningen. 